\title{
Elementary and High School Students Building Virtual Bridges to Engineering Heights with Computer Aided Design
}

\author{
David S. Cottrell \\ Pennsylvania State University at Harrisburg
}

\section{$\underline{\text { Introduction }}$}

This paper describes a work in progress. Direct coordination with school officials has authorized the use of a computer-aided design (CAD) software package originally developed as a vehicle for outreach to primary and secondary school students. This application research examines the successful initial implementation at the High School level and provides a status report on outreach efforts to fifth grade students enrolled in a program for gifted students. Although originally scheduled for completion in December, 2003, final implementation of this program will be realized in May, 2004. The students enrolled in this research effort will employ a CAD program designed to accomplish the following:

- Stimulate interest in engineering and design.

- Provide the user with an opportunity to perform a legitimate structural design, based on a realistic set of design specifications and constraints.

- Provide participants with an opportunity to use the computer as a problemsolving tool.

These students pursue a relatively simple objective: create and optimize bridge designs in seven categories featuring a variety of bridge spans and configurations. This paper provides an overview of this initiative to these High School and Grade School students.

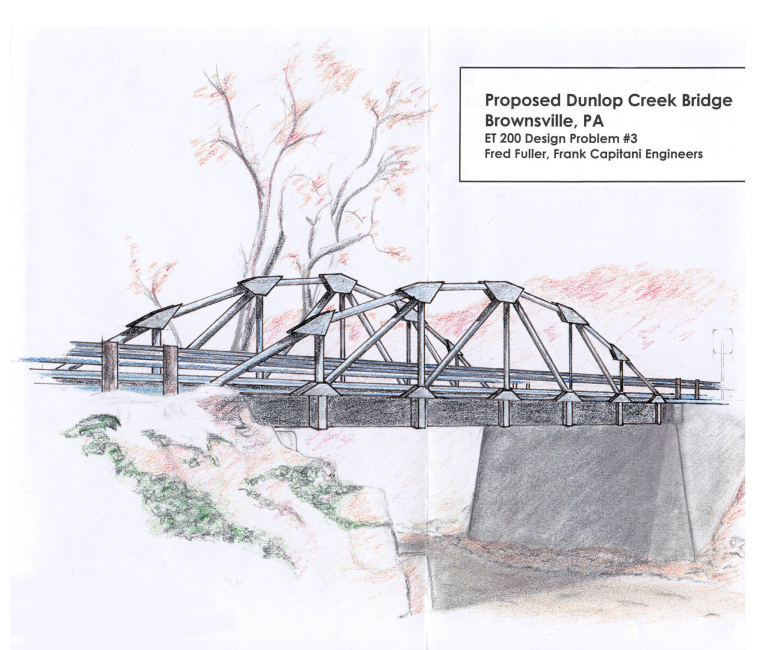

Figure 1. Student Rendering of the Howe Truss Bridge from the West Point Bridge Designer. 


\section{The Computer-Aided Design Software Program and Design Methodology}

\section{Called the West Point Bridge}

Designer, the software for this effort was actually developed to support a nation-wide competition that run annually commencing in November 2001. Nevertheless, the software has been used in multiple educational venues for both high school and college engineering students since its original conception in 1997 as a vehicle for outreach. ${ }^{5}$ Applications have been successfully employed for middle schools, ${ }^{3}$ for high schools, ${ }^{2}$ and for first year college engineer students. ${ }^{1,4}$ Using the $200^{\text {th }}$ birthday of the United States Military Academy as a target of opportunity, the West Point "Bicentennial Engineering Design Contest" provided a computer based framework for designing bridges similar to the one depicted in Figure 1 and those in Figure 2. Aimed at promoting math, science, and technology education in elementary and secondary schools, students in Kindergarten through $12^{\text {th }}$ grade throughout the United States working individually or in teams of two compete for prizes ranging from laptop computers to $\$ 15,000$ scholarships.

Although the West Point Bridge Designer software ultimately serves as the linchpin for the nation-wide contest, it is nevertheless available as free shareware from the West Point web site (http://bridgecontest.usma.edu). The software is quite powerful and, for the young budding engineer, very interactive and enticing. The software effectively guides the user through the design of a variety of truss-type highway bridges in seven separate and distinct configurations and spans as shown in Figure 2. The software also provides templates for multiple variations in the types of trusses available for each bridge category allowing for a total of 34 possible independent bridge initial designs. Each design iteration includes - at an elemental level - all of the fundamental aspects of design as defined in the ABET accreditation criteria. The projects are based on real-world scenarios; they are open-ended, permitting many possible solutions; and they require formulation of problem-solving methodologies as well consideration of alternatives and economic concerns relating to the finished project. The final structure designed and optimized by the students must be a simply supported truss of a specified span length, a maximum height restriction, and minimum clearance over the high water level of the creek. Within these bounds the user has complete freedom to define the shape and

"Proceedings of the 2004 American Society for Engineering Education Annual Conference \& Exposition Copyright (C) 2004, American Society for Engineering Education"” 
configuration of the structure. The design must be capable of carrying its own weight and the weight of a standard AASHTO truck loading. The principle design objective is to minimize cost.

The students employ an iterative design methodology that allows them to experience the engineering design process in a simplified but essentially equivalent manner that practicing civil engineers design real highway bridges. During each of the seven different design projects, students design a steel truss bridge to carry a two-lane highway across a river. Each design carries a unique set of site conditions for consideration and follows a specific methodology noted here:

- Students develop an initial bridge design by constructing a drawing on the computer screen usually based on a template provided by the software. The computer template provides guidance on location of truss joints or nodes and employs a generally acceptable default size for truss members that will produce a viable design.

- Once the first design attempt is completed, the student directs the West Point Bridge Designer software to test the bridge to verify it is strong enough to carry the specified highway loads. The test includes a full-color animation depicting a truck crossing the bridge. If the design is strong enough, the truck crosses successfully; if not, the structure collapses.

- If the bridge collapses, the software automatically highlights the truss members that failed during the load test. The student strengthens the bridge by changing the types of steel, adjusting the sizes of the structural components that make up the bridge, or by modifying the configuration of the bridge itself.

- Once the bridge successfully carries the loading without collapsing, students continue to refine the design to minimize cost while still ensuring that it can carry the specified loads.

The West Point Bridge Designer gives the student complete flexibility to create designs using any shape or configuration. Creating and improving designs is fast and easy so students can ably experiment with many different alternative configurations as they work toward the best possible solution to each of the seven categories of bridge design. In many cases, it is not uncommon for students to rapidly develop hundreds of design iterations the student feels confident that the design is complete and a high level of economy achieved. Further, their enthusiasm for engineering as a field is expected to be heightened as the process parallels so closely those procedures used by practicing civil engineers as they design real structures. In fact, the West Point Bridge Designer itself is quite similar to the computer-aided design (CAD) software used by practicing engineers, and serves in the same way that CAD software helps them - by taking care of the heavyduty mathematical calculations, so that they can concentrate on the creative part of the design process.

"Proceedings of the 2004 American Society for Engineering Education Annual Conference \& Exposition Copyright (C) 2004, American Society for Engineering Education" 


\section{Implementation Methodology}

Implementing this research effort focused on integrating the CAD bridge design program into existing academic programs first at the high school level and then with the Grade School students students. The high school students were recruited through a bridge design contest limited to students in grades 9 through 12 . The high school contest encompassed three sequential phases for execution (see Figure 3). Phase I - Introduction and Program Overview - began appropriately with the High School principal with several follow-on meetings with interested science and math teachers. As participation was essentially voluntary, Phase I also included marketing initiatives to broaden the target audience. Flyers like the one shown in Figure 4 effectively generated interest and encouraged wide participation throughout the student body. Science clubs and veterans of the recently concluded High School Science Olympiad competition provided a fertile group for enlisting apt participants as well. Further, some academic courses offered incentives to students in the form of extra credit for participation in the contest. Introduction to the software stimulated the students' intellectual curiosity about the design parameters employed by the computer. This prompted several group discussions dealing specifically with some of the more basic design fundamentals and their role is potentially optimizing a bridge design. Phase II - Bridge Development provided tutelage and support as students began working either individually or in pairs to develop their bridge designs. The CAD program provided initial starting points for the students with default settings that generated the base costs show in Table 1. The students produced designs to ultimately reduce these costs. Phase III - Final Judging - featured outcome assessments of student submittals, completed bridge designs created through the application of the CAD software. Viable designs were judged with a monetary yardstick with victory
Table 1. Bridge Configurations and Associated Base Costs Resulting from Default Program Settings

\begin{tabular}{|c|c|c|}
\hline Bridge Type & Span & $\begin{array}{c}\text { West Point } \\
\text { Bridge Designer } \\
\text { Base Costs }\end{array}$ \\
\hline $\begin{array}{c}\text { Single Span } \\
\text { Truss }\end{array}$ & $24^{\text {meters }}$ & $\$ 4,860.02$ \\
\hline $\begin{array}{c}\text { Two-Span } \\
\text { Truss }\end{array}$ & $44^{\text {meters }}$ & $\$ 12,417.45$ \\
\hline $\begin{array}{c}\text { Arch Truss } \\
\text { meters }\end{array}$ & $\$ 9,998.70$ \\
\hline $\begin{array}{c}\text { Single Span } \\
\text { with Anchorage }\end{array}$ & $48^{\text {meters }}$ & $\$ 17,303.20$ \\
\hline $\begin{array}{c}\text { Two-Span } \\
\text { with Anchorage }\end{array}$ & $56^{\text {meters }}$ & $\$ 13,361.93$ \\
\hline
\end{tabular}


awarded based on the most economic designs. Throughout the bridge design process, the software automatically tracks the total cost of the bridge as the design team works through iterations to modify and optimize the design.

Implementing this research in the Grade School will essentially follow a similar sequentially phased program (see Figure 3) discussed earlier with the High Schoolers. Phase I has already begun initially with the teacher responsible for the gifted program with several follow-on meetings to further develop a familiarity of the teacher with the software. This prompted several group discussions dealing specifically with some of the more basic design fundamentals and their role is potentially optimizing a bridge design. Phase II involves direct interaction with the students, providing tutelage and support as they begin working either individually or in pairs to develop their bridge designs. Phase II is currently scheduled to begin in May, 2004, and will take place in a computer lab at the Grade School and will be completed over a week's time. The students will ultimately produce designs to reduce the costs noted above in Table 1. Phase III will feature outcome assessments of student submittals, completed bridge designs created through the application of the CAD software. Viable designs will be judged with a monetary yardstick with victory awarded based on the most economic designs. Throughout the bridge design process, the software automatically tracks the total cost of the bridge as the design team works through iterations to modify and optimize the design.

\section{$\underline{\text { Research Results }}$}

Figure 4 compares the final design results for each of the seven bridge configurations from the high school implementation. Table 2 provides additional descriptive statistics related to economic design results along with the collective average number of iterations and design improvement for each category. Design improvement refers to the decrease in design cost as a percentage of the original vase cost. These results testify to the success of the students in interacting with the CAD program to create new designs with significant reductions in economic cost. Further, the final assessment of over seventy design submittals demonstrated the inherent flexibility of the program to

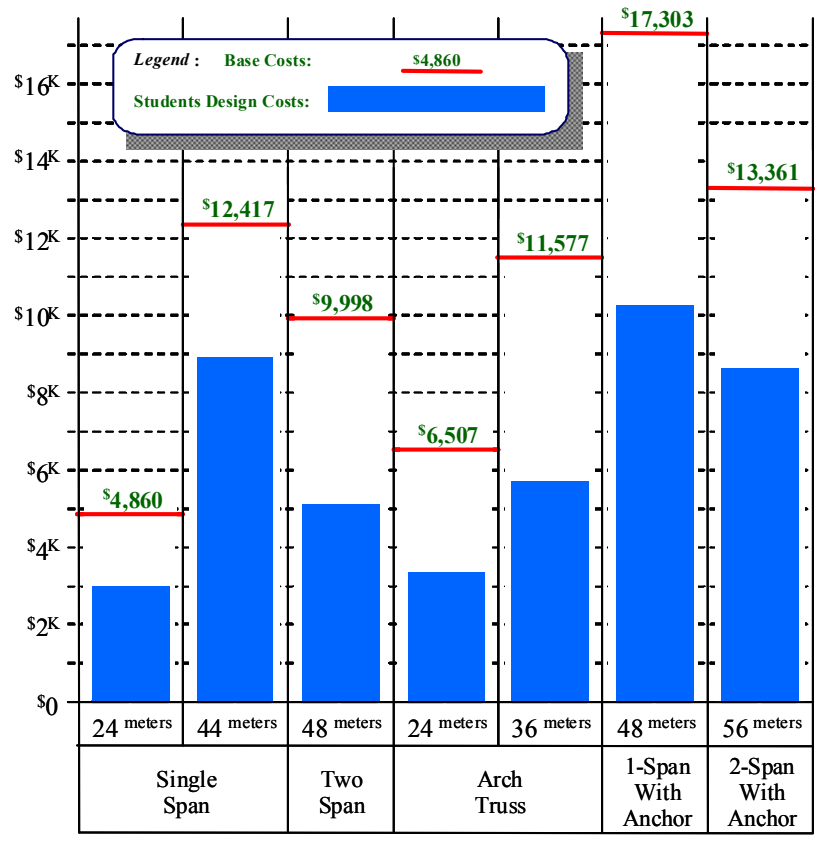

Figure 4. Comparison of High School Winning Designs with the Initial Base Design Cost for Each of the Seven Bridge Categories accommodate the individuality of 
Table 2. High School Student Design Summary

\begin{tabular}{|c|c|c|c|c|c|c|}
\hline \multirow{2}{*}{$\begin{array}{l}\text { Bridge } \\
\text { Type }\end{array}$} & \multirow{2}{*}{ Span } & \multicolumn{3}{|c|}{ Design Costs } & \multirow{2}{*}{$\begin{array}{c}\text { Average } \\
\text { Number } \\
\text { of Design } \\
\text { Iterations }\end{array}$} & \multirow{2}{*}{$\begin{array}{c}\text { Average } \\
\text { Percent } \\
\text { Design } \\
\text { Improvement }\end{array}$} \\
\hline & & High & Low & Mean & & \\
\hline \multirow{2}{*}{ Single Span } & $24^{\mathrm{m}}$ & $\$ 4,821$ & $\$ 3,033$ & $\$ 3,869$ & 44.1 & $20.4 \%$ \\
\hline & $44^{\mathrm{m}}$ & $\$ 12,388$ & $\$ 8,967$ & $\$ 10,945$ & 30.1 & $11.9 \%$ \\
\hline Two Span & $48^{\mathrm{m}}$ & $\$ 9,991$ & $\$ 5,171$ & $\$ 7,648$ & 15.5 & $23.5 \%$ \\
\hline \multirow{2}{*}{ Arch } & $24^{\mathrm{m}}$ & $\$ 6,501$ & $\$ 3,342$ & $\$ 5,654$ & 18.5 & $13.1 \%$ \\
\hline & $36^{\mathrm{m}}$ & $\$ 11,567$ & $\$ 5,699$ & $\$ 9989$ & 19.7 & $13.7 \%$ \\
\hline $\begin{array}{c}\text { Single Span } \\
\text { w/Anchor }\end{array}$ & $48^{\mathrm{m}}$ & $\$ 17,290$ & $\$ 10,272$ & $\$ 14,544$ & 22.9 & $16.0 \%$ \\
\hline $\begin{array}{l}\text { Two Span } \\
\text { w/Anchor }\end{array}$ & $56^{\mathrm{m}}$ & $\$ 13,319$ & $\$ 8,640$ & $\$ 11,773$ & 18.8 & $11.9 \%$ \\
\hline
\end{tabular}

the student. Not a single redundancy occurred; every bridge was unique, differing in size, shape, configuration, or cost. Creating and improving designs proved to be fast and easy, and students ably experimented with many different alternative configurations as they worked toward their best possible solution.

Future results from this ongoing research effort and implementation at the Grade School level will be presented at the ASEE convention. In a similar manner as those presented for the high school students, analysis will compare the final designs for each of the seven bridge configurations with descriptive statistics relating economic design results along with the collective average number of iterations and design improvement for each category. A second area of interest will compare the degree of design success of the Grade Schoolers with the results of the high school students already presented above.

\section{Conclusion}

The initial difficulty in securing access to a public school is finding a champion inside the school for the effort. At this scholastic level, students and even perhaps the teachers themselves labor under a misconception that they have no engineering experience or expertise either academically or otherwise; consequently, ongoing research like the one reported here may in some instances be difficult to initiate. Nevertheless, once exposed to the software and some of the basic underlying engineering fundamentals, teachers and students alike are usually astounded at the sophisticated level of common sense involved with engineering design methodology. As a result, engineering as a field typically becomes less mystical and remote and more "reachable" to the students and teachers alike. Students initially lukewarm to engineering as a possible field can often develop contagious enthusiasm, seriously this as a possibility for college studies. 
The use of the West Point Bridge Designer as a tool for outreach has proven to be effective in several areas. As already described, it typically leads students to take a second look at engineering as a viable field of study - even at very young ages such as the third and fourth graders targeted by this effort. Teachers likewise enjoy having the computer software medium to personally explore the tenets of engineering. Further, they also sincerely enjoy the experience of watching the students as they get turned on to this new avenue of learning. Finally, this outreach has already fostered a renewed working relationship between the local school faculty and the University as cooperative partners in education.

\section{Bibliography}

1. Jahan, Kaiser, Ralph A. Dusseau, and John S. Schmalzel, "Introducing Civil Engineering Measurements though Bridges," Proceedings of the 1998 American Society for Engineering Education Annual Conference \& Exposition.

2. Johnson, Eric W., "Time Engineers: An Interactive Multi-media Prodram for Secondary School Students," Proceedings of the 2000 American Society for Engineering Education Annual Conference \& Exposition.

3. Lee, Lana Wah, and Tamer Ceylan, "Strengthening the Pipeline - A workshop for Middle School Mathematics and Science Teachers," Proceedings of the 2000 American Society for Engineering Education Annual Conference \& Exposition.

4. Orabi, Ismail I., "Outcomes Assessment Results of a Multi-disciplinary First-year Engineering Course at the University of New Haven," Proceedings of the 1999 American Society for Engineering Education Annual Conference \& Exposition.

5. Ressler, Stephen J., Kip N. Nygren, and Christopher H. Conley, "Building Bridges: Computer-Aided Design as a Vehicle for Outreach to High School Students," Proceedings of the 1997 American Society for Engineering Education Annual Conference \& Exposition.

DR. DAVID S. COTTRELL is an Assistant Professor in the School of Science and Engineering Technology at Pennsylvania State University at Harrisburg. He graduated from the United States Military Academy in 1978 and retired in 2000 after 22 years of service with the US Army Corps of Engineers. Studies at Texas A\&M University resulted in an MS Degree in Civil Engineering in 1987 and a PhD in 1995. He is a registered Professional Engineer and has taught courses in statics, dynamics, mechanics of materials, graphic communications, engineering economy, and construction planning, scheduling, estimating, and management.

"Proceedings of the 2004 American Society for Engineering Education Annual Conference \& Exposition Copyright (C) 2004, American Society for Engineering Education" 